\title{
Mastite subclínica e relação da contagem de células somáticas com número de lactações, produção e composição química do leite em vacas da raça Holandesa
}

\author{
[Subclinical mastitis and the relationship between somatic cell count with number of lactations, \\ production and chemical composition of the milk] \\ R.P.L. Cunha ${ }^{1}$, L.R. Molina ${ }^{2}$, A.U. Carvalho ${ }^{2}$, E.J. Facury Filho ${ }^{2}$,
P.M. Ferreira ${ }^{2}$, M.B. Gentilini ${ }^{3}$. \\ ${ }^{1}$ Médico veterinário autônomo \\ ${ }^{2}$ Escola de Veterinária - UFMG - Belo Horizonte, MG \\ ${ }^{3}$ Aluno de graduação - EV-UFMG - Belo Horizonte, MG
}

\begin{abstract}
RESUMO
Verificaram-se a ocorrência de mastite subclínica em animais da raça Holandesa e a relação entre a contagem de células somáticas com a ordem de lactação e com a produção e a composição química do leite. $\mathrm{O}$ estudo foi realizado em propriedades integrantes do programa de controle leiteiro da Associação de Criadores de Gado Holandês de Minas Gerais. As variáveis estudadas foram: ordem de lactação, ocorrência de mastite subclínica, contagem de células somáticas (CCS), produção de leite e porcentagens de gordura e de proteína total. A correlação entre CCS e produção de leite foi negativa e entre CCS e porcentagens de gordura e de proteína, positivas. Animais com maior número de lactações apresentaram maior CCS, e com CCS acima de 100.000 cels/ml menor produção de leite.
\end{abstract}

Palavras-chave: gado de leite, contagem de células somáticas, mastite, produção de leite

\begin{abstract}
The subclinical mastitis occurrence and the relationship between somatic cell count (SCC) with parity, milk yield and milk chemical composition, were studied in Holstein cows. The study was carried out in farms belonging to the milk control program of the Associação de Criadores de Gado Holandês de Minas Gerais. Data on lactation order, subclinical mastitis, SCC, milk production, fat contents and total protein contents were analyzed. There was a negative correlation between SCC and milk production and, correlations between SCC and percentage of fat and protein were positive. Higher lactation order cows showed higher SCC, and cows with SCC higher than 100,000 cels/ml showed less milk production.
\end{abstract}

Keywords: dairy cattle, somatic cell count, mastitis, milk yield

\section{INTRODUÇÃO}

O perfil da indústria de leite e derivados está mudando no Brasil, e o País está passando de importador para exportador do produto. Em 2000, o país importou 373 milhões de dólares em leite e derivados, sendo 256 milhões de leite em pó, creme de leite e leite concentrado. Em 2003, importou 112 milhões de dólares em leite e derivados, sendo 71 milhões de leite em pó, creme de leite e leite concentrado, isto é, houve redução de $70 \%$ nos valores de importação (Anuário..., 2004).

A mastite subclínica está entre as principais doenças em fazendas leiteiras, causando grandes prejuízos aos produtores, principalmente devido à redução na produção de leite (Ruegg, 2003; Zafalon et al., 2007). Essa redução ocorre devido a alterações nas células epiteliais secretoras e na

Recebido em 7 de novembro de 2006

Aceito em 18 de dezembro de 2007

E-mail: rodrigoplc@yahoo.com.br 


\section{Cunha et al.}

permeabilidade vascular no alvéolo secretor durante a infecção. A extensão da perda é influenciada por diversos fatores como gravidade da infecção, tipo de microrganismo causador, duração, idade do animal, época do ano, estado nutricional e potencial genético. À medida que a ordem e o estágio de lactação avançam, são observados aumentos na contagem de células somáticas (CCS) em razão da maior resposta celular de vacas adultas à ocorrência de mastite subclínica, aumento da prevalência de infecções e lesões residuais de infecções anteriores (Schultz, 1977). Segundo Coldebella (2003), vacas multíparas sofrem maiores perdas, como resultado dos danos permanentes à glândula mamária por infecções prévias, além de apresentarem infecções mais prolongadas, que resultam em maiores danos ao tecido mamário. Assim, a ocorrência de mastite pode resultar em perdas de produção não só na lactação atual, mas também na lactação seguinte, comprometendo a produção total do animal. As estimativas das perdas de produção podem variar de 10 a $30 \%$ da produção leiteira por lactação (Auldist e Hubble, 1998).

A mastite subclínica determina, ainda, mudanças na concentração dos principais componentes do leite, como: proteína, gordura, lactose, minerais e enzimas. Os principais fatores relacionados com a alteração dos componentes do leite são as lesões das células produtoras de leite, que podem resultar em alterações da concentração de lactose, proteína e gordura, e aumento da permeabilidade vascular, que determina o aumento da passagem de substâncias do sangue para o leite, tais como sódio, cloro, imunoglobulinas e outras proteínas séricas (Steffert, 1993).

Devido aos prejuízos causados pela mastite subclínica mediante redução na produção e na qualidade do leite, este estudo teve como objetivo verificar a ocorrência de mastite subclínica em animais da raça Holandesa e a relação entre a CCS e o número de lactações, e entre a CCS e a produção e composição química do leite.

\section{MATERIAL E MÉTODOS}

$\mathrm{O}$ estudo foi realizado em propriedades integrantes do programa de controle leiteiro da Associação de Criadores de Gado Holandês de
Minas Gerais (ACGHMG). Entre 2000 e 2003, foi realizado, mensalmente, acompanhamento de fazendas com pesagem de leite e coleta de amostras para análise da composição do leite de animais da raça Holandesa. As amostras, coletadas em todas as ordenhas em medidores de leite, foram encaminhadas em frascos com conservante Bronopol (2-bromo-2-nitropropano1,3-diol) para análise da porcentagem de gordura e porcentagem de proteína total pelo método infravermelho, utilizando-se equipamento eletrônico Bentley ${ }^{1}$ 2000. Para a CCS, utilizou-se o método de citometria de fluxo por meio do equipamento eletrônico Somacount ${ }^{1}$ 300. Os animais que apresentaram CCS acima de $250.000 \mathrm{cel} / \mathrm{ml}$ de leite foram considerados portadores de mastite clínica, de acordo com Andrews et al. (1983).

As variáveis dependentes e quantitativas foram produção de leite, CCS, porcentagem de gordura e porcentagem de proteína total, todas em função de: núcleo, ano, mês, ordem de lactação e eventuais interações. A normalidade das variáveis foi testada por meio do teste Lilliefors. Para estas análises, os dados de CCS, por não apresentarem distribuição normal, foram transformados em Log na base 10.

A variável qualitativa diagnóstico de mastite subclínica teve sua dispersão estudada segundo núcleo, mês, ano e ordem de lactação, por meio de tabelas de contingência e conseqüente teste do qui-quadrado $\left(X^{2}\right)$. Para estudar a associação entre os valores de CCS com as demais variáveis dependentes, os animais foram agrupados em classes de acordo com a CCS $(\leq 100,101-250$, 251-500, 501-750, 751-1000, 1001-1500, 15013000 e > 3000) aplicando-se a correlação de Pearson. As análises estatísticas foram realizadas no programa SAEG 8.0 (Sistema..., 2000).

\section{RESULTADOS E DISCUSSÃO}

Houve redução progressiva $(\mathrm{P}<0,05)$ na porcentagem de animais com mastite subclínica entre os anos de $2000(43,9 \%)$ e 2003 (38,7\%), como mostrado na Tab.1.

${ }^{1}$ Bentley Instruments Incorporated - Minneapolis, EUA 
Tabela 1. Ocorrência (\%) de mastite subclínica em vacas de leite segundo os anos estudados

\begin{tabular}{cc}
\hline Ano & Mastite subclínica \\
\hline 2000 & $43,9 \mathrm{C}$ \\
2001 & $44,0 \mathrm{C}$ \\
2002 & $43,1 \mathrm{~B}$ \\
2003 & $38,7 \mathrm{~A}$ \\
\hline
\end{tabular}

Valores seguidos por letras distintas diferem pelo teste qui-quadrado $(\mathrm{P}<0,05)$.

Este resultado pode ser atribuído ao maior rigor na obtenção de leite visando à exportação e maior exigência do mercado interno. De fato, a partir da Instrução Normativa Número 51, de 18 de setembro de 2002, em que foram estabelecidos padrões mínimos de qualidade de leite, houve maior preocupação dos laticínios em analisar parâmetros de qualidade do leite dos produtores, oferecendo bonificação àqueles que se enquadravam nos parâmetros estabelecidos pela Normativa. Este fator pode estar relacionado com a redução da mastite subclínica nas regiões estudadas.

Nos núcleos da ACGHMG, observa-se que a porcentagem de mastite subclínica, nas regiões estudadas, variou de 40,5\% (ACRICOM) a $54 \%$ (NUGHOMAN) (Tab.2). Outros trabalhos realizados em Minas Gerais apresentaram variação de 20,8 \% (Prado et al., 1997) a 72,6\% (Costa et al., 1995). Essa variação entre os núcleos estudados pode estar relacionada às características de manejo de ordenha, nutricional e sanitário.
Tabela 2. Ocorrência (\%) de mastite subclínica segundo o núcleo da Associação de criadores de gado Holandês de Minas Gerais

\begin{tabular}{cc} 
Núcleo & Mastite subclínica \\
\hline ACRICOM & $40,5 \mathrm{~A}$ \\
ACRILEITE & $40,8 \mathrm{AB}$ \\
NUGHOMARJ & $41,9 \mathrm{BC}$ \\
NUCRISUL & $42,9 \mathrm{CD}$ \\
NUGHOBAR & $43,6 \mathrm{DE}$ \\
NUARG & $44,6 \mathrm{E}$ \\
NUGHOMAN & $54,0 \mathrm{~F}$
\end{tabular}

Valores seguidos por letras distintas diferem pelo teste qui-quadrado $(\mathrm{P}<0,05)$.

Os resultados de CCS, produção de leite, porcentagem de gordura e porcentagem de proteína em relação ao número de lactações são apresentados na Tab.3. Houve aumento progressivo na CCS com o aumento da ordem de lactação. Estes resultados são semelhantes aos de Natzke et al. (1972) e Bodoh et al. (1976). Conforme Shultz (1977), a elevação da CCS no leite de vacas com maior número de lactações poderia ser parcialmente explicada pelo aumento de células epiteliais no leite em vacas mais velhas, além de maior taxa de infecção da glândula mamária.

Tabela 3. Contagem de células somáticas (LogCCS), produção de leite e porcentagens de proteína e gordura em vacas da raça Holandesa, segundo a ordem de lactação

\begin{tabular}{|c|c|c|c|c|c|}
\hline $\begin{array}{c}\mathrm{N}^{\circ} \text { de } \\
\text { amostras }\end{array}$ & $\begin{array}{l}\text { Ordem da } \\
\text { lactação }\end{array}$ & $\begin{array}{c}\log \\
(\mathrm{CCS} / 1000)^{1}\end{array}$ & $\begin{array}{c}\text { Produção de leite } \\
(\mathrm{kg} / \mathrm{dia})^{2}\end{array}$ & Proteína $(\%)^{3}$ & Gordura $(\%)^{4}$ \\
\hline 62.449 & 1 & $1,95 \mathrm{D}$ & $21,7 \mathrm{D}$ & $3,15 \mathrm{~B}$ & $3,53 \mathrm{~A}$ \\
\hline 42.657 & 2 & $2,20 \mathrm{C}$ & $24,0 \mathrm{C}$ & $3,18 \mathrm{~A}$ & $3,52 \mathrm{~B}$ \\
\hline 27.004 & 3 & $2,32 \mathrm{~B}$ & $25,3 \mathrm{~A}$ & $3,13 \mathrm{C}$ & $3,50 \mathrm{C}$ \\
\hline 16.069 & 4 & $2,42 \mathrm{~B}$ & $25,2 \mathrm{~A}$ & $3,11 \mathrm{D}$ & $3,49 \mathrm{C}$ \\
\hline 13.320 & $\geq 5$ & $2,48 \mathrm{~A}$ & $23,24 \mathrm{~B}$ & $3,08 \mathrm{D}$ & $3,54 \mathrm{C}$ \\
\hline
\end{tabular}

${ }^{1} \mathrm{CV}=37 \% .{ }^{2} \mathrm{CV}=35,4 \% .{ }^{3} \mathrm{CV}=13 \% .{ }^{4} \mathrm{CV}=20,6 \%$.

Médias seguidas de letras distintas na coluna diferem entre si pelo teste Duncan $(\mathrm{P}<0,05)$.

A produção de leite aumentou até a quarta lactação e reduziu-se posteriormente. Schutz et al. (1990) avaliaram a produção de leite e as porcentagens de gordura e proteína de animais de primeira, segunda e terceira ou mais lactações. Observaram aumento progressivo na produção de leite que, segundo os autores, foi atribuído ao 


\section{Cunha et al.}

desenvolvimento fisiológico da glândula mamária, que se completa na terceira lactação.

Houve redução progressiva nas porcentagens de proteína e gordura. Schutz et al. (1990) observaram que as variações nas porcentagens de gordura e proteína estavam relacionadas negativamente com a produção de leite. Estes resultados podem estar parcialmente relacionados à variação na produção de leite.

$\mathrm{Na}$ Tab. 4 estão os resultados da análise de correlação entre CCS, produção de leite, porcentagem de gordura e porcentagem de proteína. Observou-se correlação negativa entre CCS e produção de leite $(-0,1837)$ e positiva entre CCS e porcentagem de gordura $(0,0719)$ e CCS e porcentagem de proteína $(0,1505)$. Alta CCS indica inflamação na glândula mamária, na maioria das vezes resultante de infecção bacteriana. Segundo Auldist e Hubble (1998), não há consenso na literatura em relação ao aumento da porcentagem de proteína total no leite de animais com alta CCS, porque ocorre redução na síntese de caseína e concomitante passagem de proteínas séricas para o leite.

Observaram-se correlações negativas entre produção de leite e porcentagens de gordura ($0,2917)$ e de proteína (-0,3449). A maior correlação observada foi entre porcentagem de proteína e porcentagem de gordura $(0,3695)$.

Tabela 4. Correlação entre produção de leite, porcentagem de gordura e porcentagem de proteína e contagem de células somáticas (CCS)

\begin{tabular}{cccc}
\hline Variável & Produção de leite & $\begin{array}{c}\text { Porcentagem de } \\
\text { gordura }\end{array}$ & $\begin{array}{c}\text { Porcentagem de } \\
\text { proteína }\end{array}$ \\
\hline Produção de leite & - & - & - \\
Porcentagem de gordura & $-0,2917 *$ & - & - \\
Porcentagem de proteína & $-0,3449 *$ & $0,3695 *$ & $0,1505 *$ \\
\hline CCS & $-0,1837 *$ & $0,0719 *$ & - \\
\hline
\end{tabular}

* Significância $(\mathrm{P}<0,0001)$.

A Tab. 5 apresenta os resultados de produção de leite e das porcentagens de gordura e de proteína em relação às classes de CCS. Observou-se redução progressiva na produção de leite com o aumento do número de células somáticas no leite. Essa redução foi de $7,1 \%$ entre a classe de $\leq 101.000$ e a de $101.000-250.000$, e de $19,4 \%$ entre as classes de $\leq 101.000 \mathrm{e} \geq 3.000 .000$.

Segundo Auldist e Hubble (1998), a diminuição na produção de leite ocorre em razão das lesões causadas às células epiteliais da glândula mamária, que reduzem a capacidade de síntese e a secreção da glândula mamária. Um fator importante é a redução causada pela mastite subclínica no teor de lactose. Sabe-se que a lactose é o componente do leite com maior capacidade osmótica, por isso, a diminuição da lactose resulta na redução da produção de leite. Além disso, alguns microrganismos presentes nas infecções subclínicas podem causar obstrução de ductos na glândula mamária
(Auldist e Hubble, 1998). Rajcevic et al. (2003) observaram correlação negativa entre Log de CCS e porcentagem de lactose, $-0,423$.

Houve aumento de $6,2 \%$ na porcentagem de proteína entre os animais da classe de CCS $\geq 3.000 .000$ cels $/ \mathrm{ml}$ e os da classe $\leq 100.000$ cels $/ \mathrm{ml}$. Segundo Kitchen (1981) e Munro et al. (1984), o aumento da concentração de proteínas séricas no leite de vacas com mastite subclínica pode ser atribuído ao aumento na permeabilidade vascular em conseqüência do processo inflamatório. Os pesquisadores observaram decréscimo na concentração de caseína durante a mastite, atribuído à redução na síntese e secreção da caseína e ao aumento da degradação em função do aumento da atividade das proteinases bacterianas, dos leucócitos e do sangue. Segundo Auldist e Hubble (1998), em função do grande número de variáveis, não há consenso na literatura sobre as alterações na concentração de proteína total e conteúdo de gordura. 
Tabela 5. Produção de leite e porcentagens de proteína e gordura em vacas da raça Holandesa, segundo a classe de contagem de células somáticas (cels x 1000/ml)

\begin{tabular}{ccccc}
\hline $\mathrm{N}^{\mathrm{o}}$ de amostras & $\begin{array}{c}\text { Classe de } \\
\text { CCS x 1000 }\end{array}$ & $\begin{array}{c}\text { Produção de leite } \\
(\mathrm{kg})\end{array}$ & $\begin{array}{c}\text { Proteína } \\
(\%)\end{array}$ & $\begin{array}{c}\text { Gordura } \\
(\%)\end{array}$ \\
\hline 57.840 & $\leq 100$ & 25,3 & 3,07 & 3,46 \\
34.989 & $101-250$ & 23,5 & 3,15 & 3,53 \\
24.932 & $251-500$ & 22,6 & 3,18 & 3,55 \\
12.673 & $501-750$ & 22,2 & 3,2 & 3,55 \\
7.898 & $751-1000$ & 21,9 & 3,21 & 3,56 \\
9.017 & $1001-1500$ & 21,6 & 3,22 & 3,57 \\
10.523 & $1501-3000$ & 21,3 & 3,24 & 3,57 \\
3.627 & $>3000$ & 20,4 & 3,26 & 3,61 \\
\hline
\end{tabular}

A porcentagem de gordura aumentou de $4,3 \%$ nos animais com CCS acima de 3.000 .000 cels $/ \mathrm{ml}$ em relação aos animais com CCS inferior a 100.000 cels $/ \mathrm{ml}$. Miller et al. (1983), ao avaliarem o leite individualmente, e Mitchell et al. (1986), ao usarem o leite do tanque de expansão, verificaram aumento da porcentagem de gordura no leite com alta CCS, em função da redução na produção de leite dos animais com mastite subclínica.

\section{CONCLUSÕES}

Há grande variação na ocorrência de mastite subclínica entre os rebanhos leiteiros nas diferentes regiões de Minas Gerais. Há correlação negativa entre CCS e produção de leite e positiva entre CCS e porcentagens de gordura e de proteína. Animais com maior número de lactações apresentam maior CCS, e com CCS acima de 100.000 cels $/ \mathrm{ml}$ menor produção de leite.

\section{REFERÊNCIAS BIBLIOGRÁFICAS}

ANDREWS, R.J.; KITCHEN, B.J.; KWEE, W.S. Relationship between individual cow somatic cell count and the mastitis infection status of the udder. Austr. J. Dairy Technol., v.38, p.71-74, 1983.

ANUÁRIO da Agropecuária Brasileira. 11.ed. São Paulo: OESP Gráfica, 2004.

AULDIST, M.J.; HUBLLE, I.B. Effects of mastitis on raw milk and dairy products. Austr. $J$. Dairy Technol., v.53, p.28-36, 1998.

BODOH, G.W.; BATTISTA, W.J.; SCHULTZ, L.H. Variation in somatic cell counts in dairy herd improvement milk samples. J. Dairy Sci., v.59, p.1119-1123, 1976.

COLDEBELLA, A. Contagem de células somáticas e produção de leite em vacas holandesas confinadas. 2003. 99f. Tese (Doutorado) - Escola Superior de Agricultura Luiz de Queiroz, Universidade de São Paulo, Piracicaba, SP.

COSTA, E.O.; MELVILLE, P.A.; RIBEIRO, A.R. Índices de mastite bovina clínica e subclínica nos estados de São Paulo e Minas Gerais. Rev. Bras. Med. Vet., v.17, p.215-217, 1995.

KITCHEN, B.J. Review of the progress of dairy science: bovine mastitis: milk compositional changes and related diagnostic tests. J. Dairy Res., v.48, p.167-188, 1981.

MILLER, R.H.; EMANUELSSON, U.; PERSSON, E. et al. Relationships of milk somatic cell counts to daily milk yield and composition. Acta Agric. Scand., v.33, p.209223, 1983.

MITCHEL, G.E.; ROGERS, S.A.; HOULIHAN, D.B. The relationship between somatic cell count, composition and manufacturing properties of bulk milk. 2. Composition of farm bulk milk. Austr. J. Dairy Technol., v.41, p.9-12, 1986.

MUNRO, G.L.; GRIEVE, P.A.; KITCHEN, B.J. Effects of mastitis on milk yield, milk composition, processing properties and yield and quality of milk products. Austr. J. Dairy Technol., v.39, p.7-16, 1984.

NATZKE, R.P.; EVERETT, R.W.; POSTLE, C.S. Normal milk somatic cell counts. J. Milk Food Technol., v.35, p.261-263, 1972. 
PRADO, E.; CRUZ, F.E.R.; VIANA, F.C. Problemas sanitários do rebanho de leite: percepção dos criadores. Arq. Bras. Med. Vet. Zootec., v.49, p.19-29, 1997.

RAJCEVIC, M.; POTOCNIK, K.; LEVSTEK, J. Correlations between somatic cells count and milk composition with regard to the season. Agric. Conspec. Sci., v.68, p.221-226, 2003.RUEGG, P.L. Investigation of mastitis problems on farms - Review. Vet. Clin. N. Am.: Food Anim. Pract., v.19, p.47-63, 2003.

SISTEMA para análises estatísticas e genéticas SAEG. Viçosa: UFV, 2000.

SCHULTZ, L.H. Somatic cells in milkphysiological aspects and relationship to amount and composition of milk. J. Food Prot., v.40, p.125-131, 1977.
SCHUTZ, M.M.; HANSEN, L.B.; STEUERNAGEL, G.R. Variation of milk, fat, protein and somatic cells for dairy cattle. $J$. Dairy Sci., v.73, p.484-493, 1990.

STEFFERT, I.J. Compositional changes in cow's milk associated with health problem. In: MILK FAT FLAVOUR FORUM, 1993, Palmerston North, New Zealand. Proceedings... Palmerston North, New Zealand: New Zealand Dairy Research Institute, 1993. p.119-125.

ZAFALON, L.F.; NADER FILHO, A.; OLIVEIRA, J.V. et al. Mastite subclínica causada por Staphylococcus aureus: custobenefício da antibioticoterapia de vacas em lactação. Arq. Bras. Med. Vet. Zootec., v.59, p.577-585, 2007. 